\title{
nm23, TOP2A and VEGF expression: Potential prognostic biologic factors in peripheral T-cell lymphoma, not otherwise specified
}

\author{
WENTING HUANG ${ }^{1,2}$, ZHENG CAO $^{1}$, LINSHU ZENG ${ }^{1}$, LEI GUO ${ }^{1}$, XIUYUN LIU $^{1}$, NING LV ${ }^{1}$ and XIAOLI FENG ${ }^{1}$ \\ ${ }^{1}$ Department of Pathology, National Cancer Center/National Clinical Research Center for Cancer/Cancer Hospital, \\ Chinese Academy of Medical Sciences and Peking Union Medical College, Beijing 100021; ${ }^{2}$ Department of Pathology, \\ National Cancer Center/National Clinical Research Center for Cancer/Cancer Hospital and Shenzhen Hospital, \\ Chinese Academy of Medical Sciences and Peking Union Medical College, Shenzhen, Guangdong 518116, P.R. China
}

Received September 6, 2018; Accepted June 12, 2019

DOI: $10.3892 / 01.2019 .10703$

\begin{abstract}
Peripheral T-cell lymphoma not otherwise specified (PTCL-NOS) is an aggressive lymphoma associated with a poor outcome. To date, the factor consistently associated with prognosis is the International Prognostic Index (IPI) score; however, it is considered that the IPI score cannot be beneficial for guiding potential targeted therapies. New scoring systems have recently been developed. The aim of the present study was to observe the expression of NME/NM23 nucleoside diphosphate kinase 1 (nm23), nuclear DNA topoisomerase 2- $\alpha$ (TOP2A), multiple myeloma oncogene-1 (MUM-1) and vascular endothelial growth factor (VEGF), and evaluate their prognostic value in PTCL-NOS. A retrospective analysis of 124 cases of PTCL-NOS showed that 70/122 (57.4\%) cases were positive for $\mathrm{nm} 23,71 / 122(58.2 \%)$ for TOP2A, 30/119 (25.2\%) for MUM-1 and 64/122 (52.5\%) for VEGF. Of note, $50 / 122$ cases concurrently expressed $\mathrm{nm} 23$, TOP2A and VEGF. The univariate analysis results revealed that the $\mathrm{nm} 23(\mathrm{P}=0.012)$, TOP2A $(\mathrm{P}=0.002)$ and VEGF $(\mathrm{P}=0.008)$ expression had a negative prognostic effect in patients with PTCL-NOS, while the MUM-1 expression did not have a significant prognostic value $(\mathrm{P}=0.918)$. In addition, the concurrent expression of
\end{abstract}

Correspondence to: Dr Xiaoli Feng, Department of Pathology, National Cancer Center/National Clinical Research Center for Cancer/Cancer Hospital, Chinese Academy of Medical Sciences and Peking Union Medical College, 17 Panjiayuan Nanli, Chaoyang, Beijing 100021, P.R. China

E-mail: fengx1@cicams.ac.cn

Abbreviations: PTCL-NOS, peripheral T-cell lymphoma, not otherwise specified; TOP2A, nuclear DNA topoisomerase 2- $\alpha$; DLBCL, diffuse large B-cell lymphoma; MUM-1, multiple myeloma oncogene-1; OS, overall survival; HR, hazard ratio; IPI, International Prognostic Index

Key words: peripheral T-cell lymphoma, not otherwise specified, NME/NM23 nucleoside diphosphate kinase 1, nuclear DNA topoisomerase $2-\alpha$, vascular endothelial growth factor, prognosis, immunohistochemistry nm23, TOP2A and VEGF was significantly associated with a worse prognosis $(\mathrm{P}=0.002)$. However, in multivariate Cox regression analysis, the concurrent expression of nm23, TOP2A and VEGF tended to predict a worse prognosis, however the P-value was borderline (hazard ratio, 1.495; 95\% confidence interval, 0.993-2.250; $\mathrm{P}=0.054)$. It is speculated that there may be an association among the expression of nm23, TOP2A and VEGF, and that their expression may serve as a promising prognostic factor for PTCL-NOS.

\section{Introduction}

Peripheral T-cell lymphoma not otherwise specified (PTCL-NOS) is a relatively rare disease, accounting for $\sim 6 \%$ of all non-Hodgkin lymphomas (NHL) (1); however, it is more common in Asian than in Western countries $(2,3)$. Patients with PTCL-NOS usually present with an aggressive clinical course and poor prognosis with frequent relapses (4). Therefore, a number of immunophenotypical and biological factors have been studied to determine their prognostic and predictive role in PTCL-NOS (4).

The NME/NM23 nucleoside diphosphate kinase 1 (nm23) gene is an important metastasis suppressor gene, whose downregulation triggers metastatic progression. A number of previous studies have shown that the nm 23 protein was expressed at a low level in a variety of metastatic human carcinomas, including laryngeal squamous cell carcinoma (5), breast carcinoma (6), hepatocellular carcinoma (7) and gastric carcinoma (8), suggesting that the low expression of nm23 may increase their metastatic potential. The opposite results have been reported in lymphomas. It has been identified that aggressive NHL exhibited significantly higher expression levels of nm23 compared with indolent NHL (9-11). In addition, $\mathrm{nm} 23$ overexpression was associated with poor prognosis in aggressive lymphomas, such as diffuse large B-cell lymphoma (DLBCL) and PTCL-NOS (9-11).

Nuclear DNA topoisomerase 2- $\alpha$ (TOP2A) is an essential enzyme required for DNA replication and transcription, as it controls and alters the topological states of DNA (12). The overexpression of TOP2A in carcinomas has been shown to be a reliable proliferation marker and to suggest poor prognosis (12-15). The same results were confirmed in mantle cell 
lymphoma (16), with shorter survival in patients with higher TOP2A.

Interferon regulatory factor 4/multiple myeloma oncogene-1 (MUM-1) is a member of the interferon regulatory factor family of transcriptional factors (17). It is usually expressed in aggressive B-cell lymphomas (17). A recent study suggested that the MUM-1 expression may be associated with poor survival outcomes in patients with PTCL (18).

Vascular endothelial growth factor (VEGF) is an important signaling protein belonging to the platelet-derived growth factor family produced by cells that is involved in vasculogenesis and angiogenesis (19). VEGF may also be beneficial in the development of hematolymphoid cells (20). A number of studies have shown that VEGF overexpression was associated with a worse prognosis and tumor progression in classical Hodgkin and NHL $(21,22)$. It has been reported that elevated VEGF expression levels may be an indicator of biologically aggressive DLBCL (20).

Although the roles of nm23, TOP2A, MUM-1 and VEGF have been investigated in certain types of lymphomas, thus far, to the best of our knowledge, there have been only a limited number of studies on PTCL-NOS. The aim of the present study was to determine the expression of nm23, TOP2A, MUM-1 and VEGF in PTCL-NOS, and evaluate the clinical and prognostic significance.

\section{Materials and methods}

Case selection. All cases of T-cell lymphoma diagnosed between November 1999 and October 2011 at the National Cancer Center/National Clinical Research Center for Cancer/Cancer Hospital, Chinese Academy of Medical Sciences and Peking Union Medical College (Beijing, China) were reviewed. All cases were reclassified according to the 2017 World Health Organization classification of tumors of hematopoietic and lymphoid tissues by two experienced hematopathologists using a multi-head microscope (4). When there were different opinions regarding a case, there was discussion until an agreement was reached. A total of 124 cases [88 men and 36 women with a median age of 49 years (range, 4-88 years)] of de novo PTCL-NOS were reassessed following hematoxylin and eosin and immunohistochemical staining, and included in the study. The corresponding bone marrow aspiration smear and bone marrow biopsy slice, as well as cerebrospinal fluid smear were also reviewed by two experienced pathologists using a multi-head microscope, to identify whether tumor cells were present.

Clinical information, including age at diagnosis, gender, primary site, number and sites of involvement, Ann Arbor stage (23), International Prognostic Index (IPI) score (24), treatment regimens, response to therapy and overall survival (OS), was collected from the patients' medical records. The last follow-up date was November 16, 2017. This was a retrospective study therefore it was exempt from consent, which was approved by the Ethics Committee of the Cancer Hospital, Chinese Academy of Medical Sciences.

Immunohistochemical analysis. All the samples were fixed in $10 \%$ formalin at room temperature for 6 to $48 \mathrm{~h}$. Immunohistochemical analysis was performed on $4 \mu \mathrm{m}$ paraffin-embedded tissue sections using an autostainer, a Ventana Benchmark XT (Ventana Medical Systems, Inc), according to the manufacturer's protocols. The panel of monoclonal antibodies included nm23 (clone 37.6; cat. no. sc-56928; Genetex Santa Cruz Biotechnology, Inc.), TOP2A (clone 3F6; cat. no. MAB9689; Abnova), MUM-1 (clone MUM1p; cat.no. IS644; Agilent Technologies, Inc.) and VEGF (clone A20; cat. no. sc-152; Santa Cruz Biotechnology, Inc.). All of these four antibodies were working solution purchased from ZSGB-Bio, Beijing. The temperature for the primary antibody was $37^{\circ} \mathrm{C}$ and the duration of incubation of VEGF, NM23, and TOP2A was $32 \mathrm{~min}$, and for MUM-1 it was $1 \mathrm{~h}$. The ultraView Universal horseradish peroxidase (HRP) Mutimer (cat. no. 05269806001; Roche Diagnostics) was used as the secondary antibody and the temperature and duration of incubation was $37^{\circ} \mathrm{C}$ and $8 \mathrm{~min}$, respectively. The blocking reagent was included in the dispenser of HRP Mutimer $(<50 \mu \mathrm{g} / \mathrm{ml})$, in the ultraView Universal DAB Detection kit. The staining reagent used was the ultraView Universal DAB Chromogen (0.2\% DAB), DAB $\mathrm{H}_{2} \mathrm{O}_{2}$ $\left(0.04 \% \mathrm{H}_{2} \mathrm{O}_{2}\right)$, DAB Copper $\left(\mathrm{CuSO}_{4} 5 \mathrm{~g} / \mathrm{l}\right)$, and temperature was $37^{\circ} \mathrm{C}$, the duration of staining was $8 \mathrm{~min}$. Positive controls were used, and PBS was used as the negative control, replacing the primary antibody. nm23 and VEGF exhibited cytoplasmic staining, and TOP2A and MUM-1 nuclear staining. The cut-offs for positive nm23, TOP2A, MUM-1 and VEGF expression were $\geq 30 \%$ of tumor cells, as previously reported $(9,25)$. All samples were observed and evaluated by two experienced hematopathologists using a multi-head microscope.

Statistical analysis. OS was calculated from the date of diagnosis to the date of death of the patient from any cause or last follow-up. The one-year OS rate was calculated using the life-table method $(26,27)$. Patient survival was analyzed using the Kaplan-Meier method and compared using the log-rank test. Multivariate analysis was performed using Cox regression analysis. Clinicopathological characteristics of different groups were compared using the Fisher's exact or $\chi^{2}$ tests. Statistical analysis was performed using SPSS 18.0 software (SPSS, Inc.). $\mathrm{P}<0.05$ was considered to indicate a statistically significant difference.

\section{Results}

Clinical features. The study group included 88 men and 36 women with a median age of 49 years (range, $4-88$ years). A total of $96(77.4 \%)$ patients had extranodal disease at diagnosis and $13(13.5 \%)$ presented with $\geq 2$ extranodal sites of involvement. The extranodal sites involved included bone marrow, central nervous system (CNS), lungs, breasts, liver, spleen, skin, soft tissue, bones, small intestine and nasopharynx. Bone marrow involvement was observed in 10/97 (10.3\%) patients assessed. A total of 98 patients underwent cerebrospinal fluid analysis or imaging examination, and tumor cells in cerebrospinal fluid smear were detected in $2(2.0 \%)$ patients. The serum lactate dehydrogenase (LDH) level was elevated in 31/79 (39.2\%) patients assessed. A total of 58/104 (55.8\%) patients presented with a high Ann Arbor stage (III/IV) disease, and $16 / 66$ (24.2\%) had high-intermediate to high IPI score (Table I).

Expression of nm23, TOP2A, MUM-1 and VEGF in PTCL-NOS. nm23, TOP2A and VEGF was performed on 


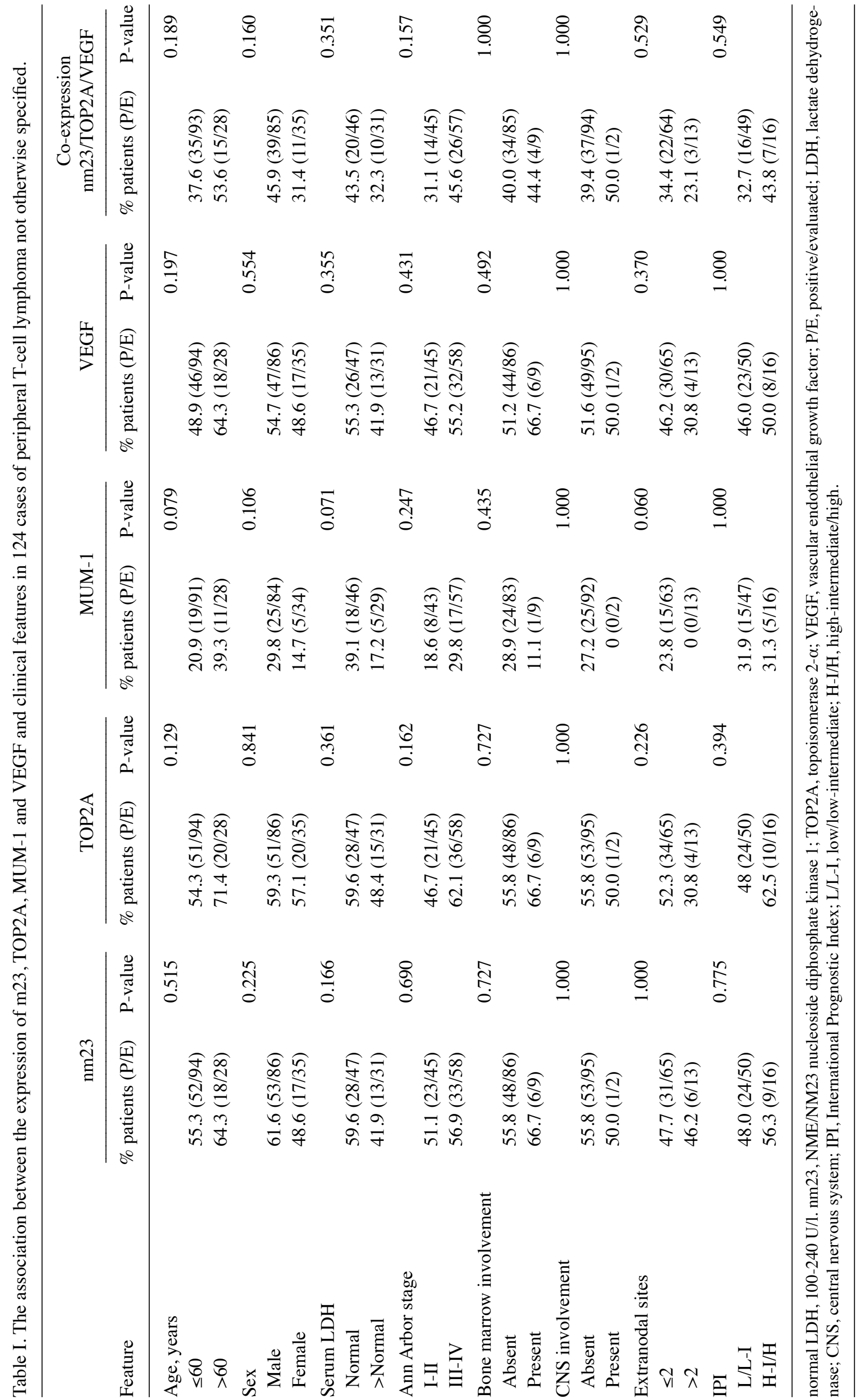




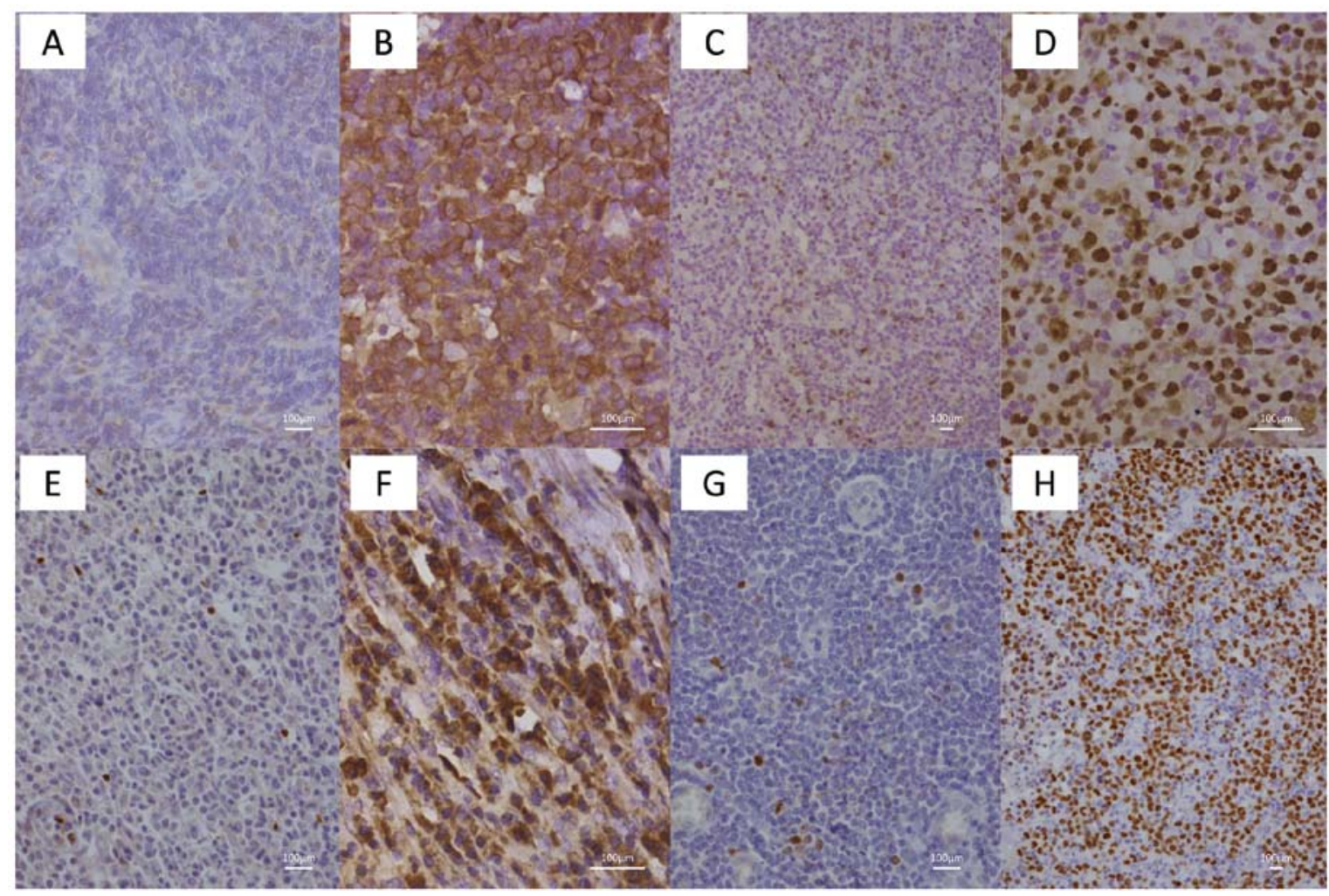

Figure 1. Immunohistochemical staining of peripheral T-cell lymphoma not otherwise specified for nm23, TOP2A, VEGF and MUM-1. (A) nm23-positive cells in the negative case, $2 \pm 2 \%$ (magnification, $\mathrm{x} 200$ ). (B) nm23-positive cells in the positive case, $90 \pm 5 \%$ (magnification, $\mathrm{x} 400$ ). (C) TOP2A-positive cells in the negative case, $10 \pm 3 \%$ (magnification, $x 100$ ). (D) TOP2A-positive cells in the positive case, $80 \pm 5 \%$ (magnification, $\mathrm{x} 200$ ). (E) VEGF-positive cells in the negative case, $3 \pm 2 \%$ (magnification, $x 200$ ). (F) VEGF-positive cells in the positive case, $50 \pm 5 \%$ (magnification, $x 400$ ). (G) MUM-1-positive cells in the negative case, $5 \pm 2 \%$ (magnification, $\mathrm{x} 200$ ). (H) MUM-1-positive cells in the positive case, 70 $\pm 5 \%$ (magnification, x100). nm23, NME/NM23 nucleoside diphosphate kinase 1; TOP2A, topoisomerase 2- $\alpha$; VEGF, vascular endothelial growth factor; MUM-1, multiple myeloma oncogene-1.

122 samples. The present study indicated that $70 / 122(57.4 \%)$ cases were positive for $\mathrm{nm} 23,71 / 122(58.2 \%)$ cases for TOP2A, 30/119 (25.2\%) for MUM-1, and 64/122 (52.5\%) for VEGF. Of note, 50/122 cases concurrently expressed nm23, TOP2A and VEGF (Fig. 1).

Association between nm23, TOP2A, MUM-1 or VEGF expression and clinicopathological features of patients with PTCL-NOS. TOP2A positivity in patients that were Ann Arbor stage I-II was 46.7\%, which was less than in Ann Arbor stage III-IV (62.1\%). However, association analysis by $\chi^{2}$ test did not show any significance $(\mathrm{P}=0.162)$. In addition, the concurrent expression of $n m 23$, TOP $2 \mathrm{~A}$ and VEGF in Ann Arbor stages I-II and III-IV were 31.1 and $45.6 \%$, respectively $(\mathrm{P}=0.157)$, with no significant difference observed. No statistical association was identified between the nm23, TOP2A, MUM-1, VEGF or concurrent nm23/TOP2A/VEGF expression and any other clinicopathological feature, including age, sex, IPI score and serum LDH level (Table I).

Prognostic analysis. Although 124 patients were enrolled in this study, 37 were lost in follow-up. With a median follow-up of 13.5 months (range, 0.0-199.0 months), $13 / 87$ (14.9\%) patients died, most of which $(11 / 13,84.6 \%)$ died within 12 months from diagnosis. The one-year OS rate was $82 \%$ calculated by using the life-table method.
The present results showed that high Ann Arbor stage (III/IV) and high-intermediate/high IPI score were associated with a worse $\mathrm{OS}(\mathrm{P}=0.034$ and $\mathrm{P}=0.032$; Fig. $2 \mathrm{~A}$ and $\mathrm{B})$. All other factors were assessed by univariate analysis for their impact on OS. It was found that the nm23, TOP2A and VEGF expression had a negative prognostic effect in patients with PTCL-NOS (Fig. 2C-E). The OS of nm23-, TOP2A- or VEGF-positive patients was significantly shorter than that of $n m 23-(\mathrm{P}=0.012)$, TOP2A- $(\mathrm{P}=0.002)$ or VEGF-negative $(\mathrm{P}=0.008)$ patients. However, MUM-1 expression was not associated with the prognosis of the patients with PTCL-NOS $(\mathrm{P}=0.918)$ (data not shown). In patients with PTCL-NOS characterized by concurrent nm23/TOP2A/VEGF expression, the OS was significantly worse than that in other patients in this cohort $(\mathrm{P}=0.002$; Fig. $2 \mathrm{~F})$. Other variables, including age, sex and serum LDH level were not associated with the OS of patients with PTCL-NOS (data not shown).

Based on the univariate analysis, nm23, TOP2A and VEGF expression, and IPI score were assessed by multivariate Cox regression analysis. The results showed that none of the variables were independent prognostic factors $(\mathrm{nm} 23, \mathrm{P}=0.751$; TOP2A, $\mathrm{P}=0.459$; VEGF, $\mathrm{P}=0.245$ ). The concurrent expression of nm23, TOP2A and VEGF, and IPI were also analyzed. It was found that the concurrent expression of nm23, TOP2A and VEGF tended to predict a worse prognosis, however the P-value was borderline [hazard ratio (HR), 1.495; 95\% confidence interval (CI), 0.993-2.250; $\mathrm{P}=0.054$ ] (Table II). 
Table II. Multivariate analysis of clinicopathological features predictive of overall survival rate in all patients with peripheral T-cell lymphoma not otherwise specified.

\begin{tabular}{|c|c|c|c|}
\hline Features & Hazard ratio & $95 \%$ confidence interval & P-value \\
\hline IPI (H-I/H vs. L/L-I) & 3.035 & $0.742-12.414$ & 0.122 \\
\hline Co-expression of nm23/TOP2A/VEGF & 1.495 & $0.993-2.250$ & 0.054 \\
\hline
\end{tabular}

IPI, international prognostic index; L/L-I, low/low-intermediate; H-I/H, high-intermediate/high; nm23, NME/NM23 nucleoside diphosphate kinase 1; TOP2A, topoisomerase 2- $\alpha$; VEGF, vascular endothelial growth factor.
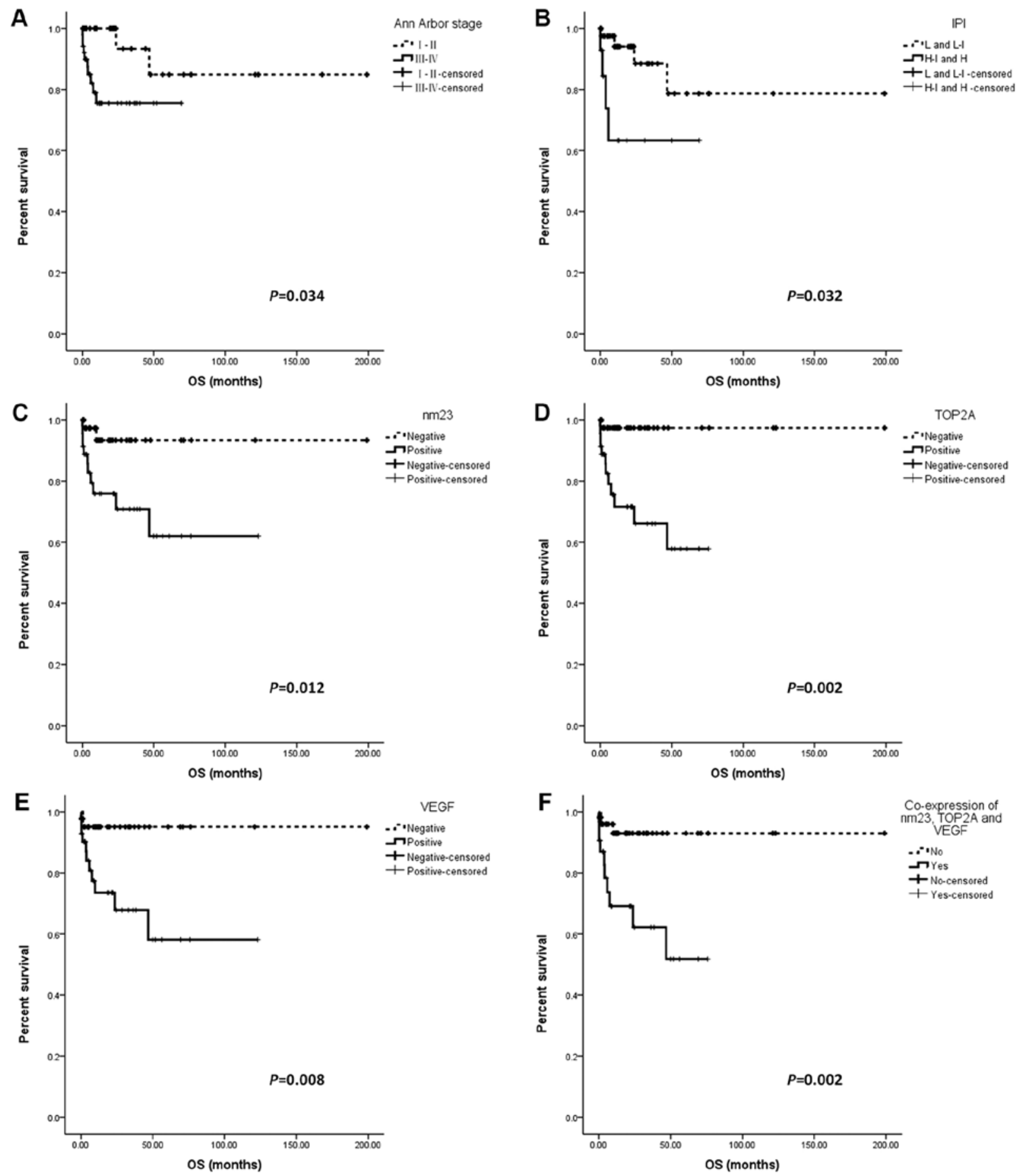

Figure 2. OS of patients with peripheral T-cell lymphoma not otherwise specified. Patients were subdivided according to (A) Ann Arbor Stage, (B) IPI, (C) nm23, (D) TOP2A, (E) VEGF and (F) concurrent nm23, TOP2A and VEGF expression. OS, overall survival; IPI, International Prognostic Index; nm23, NME/NM23 nucleoside diphosphate kinase 1; TOP2A, topoisomerase 2- $\alpha$; VEGF, vascular endothelial growth factor. 


\section{Discussion}

PTCL-NOS, accounting for $60-70 \%$ of T-cell lymphomas, does not conform to known entities of mature T-cell lymphoma in the current classification $(4,28)$. The majority of patients suffering from it are adults, and the male to female ratio is usually $2: 1$ (4). Similar to previous studies from Western and Asian countries (29-32), the median age at diagnosis of this study's cohort was 49 years, and there was a sex bias with a male to female ratio of 2.4:1.

PTCL-NOS is one of the most aggressive subtypes of NHLs, and it is associated with poor prognosis (4). Patients with PTCL-NOS more often exhibit a high Ann Arbor stage, high IPI score and more extranodal sites of involvement at diagnosis $(4,30)$. As illustrated in the present study, $55.8 \%$ of patients had high Ann Arbor stage (III/IV) disease. Furthermore, most patients (77.4\%) presented with extranodal sites of involvement, and $13.5 \%$ with $\geq 2$ extranodal sites of involvement. It has been reported that the 3-year OS rate of PTCL-NOS was $\sim 40 \%$ and the 5-year OS rate was $\sim 30 \%(33,34)$. Recently, a small cohort study on a Japanese population with PTCL-NOS reported a 2 -year OS rate of $61 \%$ (29). In this study, there were 37 patients lost to follow-up. Since a number of the present cases had a short follow-up time (median follow-up, 13.5 months), only the 1-year OS rate was assessed using the life-table method, which was found to be $82 \%$. In addition, $13 / 87(14.9 \%)$ patients in this cohort succumbed to the disease, most of them $(11 / 13,84.6 \%)$ within 12 months from diagnosis. Therefore, the present results also provided evidence that patients with PTCL-NOS have an aggressive clinical progress, generally consistent with previous reports $(35,36)$. It has been reported that the median time of failure-free survival was only 3.1 months (35), and nearly half of the patients experienced relapse or progression within 6 months after primary therapy (36).

Although many studies evaluating the contribution of clinical and biological factors in influencing the prognosis of PTCL-NOS have been performed, IPI score remains the most commonly used and effective predictive prognostic factor $(37,38)$. In the past few years; however, several studies have demonstrated that IPI score did not effectively predict the prognosis of PTCL-NOS $(28,39)$. Furthermore, it is considered that the IPI score does not provide specific biological insight or potential targets for drug therapy (28). Therefore, various prognostic models of PTCL-NOS have been investigated in previous studies, each of which incorporated different clinical parameters $(31,34)$. Similar to IPI score, these prognostic models also did not include tumor-specific biological factors, and can therefore not be used for targeted therapies (31,34).

nm23, TOP2A, MUM-1 and VEGF are very common markers used to estimate the progression, infiltration and metastasis ability of many malignant tumors, particularly carcinomas (14,40-44). Although their prognostic role in various carcinomas has been widely investigated over time, such as breast (45), pancreatic (12) and renal cell carcinoma (42), to the best of our knowledge, a limited number of have focused on their value in lymphomas.

In the present study, the expression of nm23, TOP2A, MUM-1 and VEGF was examined in 122 cases of PTCL-NOS. The association between their expression and clinicopathological features, as well as their prognostic value, was analyzed. It was found that $57.4 \%$ cases were positive for $n m 23$, which was slightly higher than in other studies $(9,46)$. Similar to the nm23 expression, $>50 \%$ of cases were positive for TOP $2 \mathrm{~A}(58.2 \%)$ and VEGF $(52.5 \%)$. Of note, 50/122 (41.0\%) cases concurrently expressed nm23, TOP2A and VEGF. This study therefore speculated that there may be an association among them. Further studies are required to illustrate the mechanism of their interactions. No significant difference was observed between the expression of nm23, TOP2A, MUM-1 or VEGF, and clinicopathological characteristics.

Consistent with several previous studies $(9,46,47)$, the univariate analysis results showed that the expression of $\mathrm{nm} 23$, TOP2A and VEGF was associated with a poor prognosis in patients with PTCL-NOS. Similarly, concurrent $\mathrm{nm}$ 23/TOP2A/VEGF expression predicted a worse prognosis for patients with PTCL-NOS. However, multivariate Cox regression analysis revealed that only concurrent nm23/TOP2A/VEGF expression was usually associated with an inferior outcome in patients with PTCL-NOS, however no significance was observed. Due to the short follow-up time in this cohort, further studies are required.

In conclusion, the present results indicated that the expression of nm23, TOP2A and VEGF could serve as a promising prognostic factor for PTCL-NOS, and could be included in an effective prognostic model for PTCL-NOS. In addition, the development of novel treatments targeting nm23, TOP2A and VEGF is required for patients diagnosed with PTCL-NOS.

\section{Acknowledgements}

Not applicable.

\section{Funding}

This research was supported by the Capital Clinical Characteristic Application Research (grant no. Z141107002514046) from Beijing Municipal Science \& Technology Commission.

\section{Availability of data and materials}

The datasets used and/or analyzed during the current study are available from the corresponding author on reasonable request.

\section{Authors' contributions}

WH contributed to experiment guidance, data analysis and manuscript writing. ZC and LZ contributed to clinical follow-up and acquisition of clinical data. LG contributed to tissue collection and performing immunohistochemistry staining. XL contributed to immunohistochemistry staining. NL contributed to the study design. XF contributed to coordination, discussion and manuscript editing, and provided data interpretation. All authors commented on the manuscript and have read and approved the final version of this manuscript.

\section{Ethics approval and consent to participate}

This study was a retrospective study, and the ethics approval of this study was obtained from the Independent Ethics 
Committee of Cancer Hospital, Chinese Academy of Medical Sciences, National GCP Center for Anticancer Drugs (approval no. NCC2014ST-08).

\section{Patient consent for publication}

Not applicable.

\section{Competing interests}

The authors declare that they have no competing interests.

\section{References}

1. You JM: Peripheral T-cell Lymphoma, Not Otherwise Specified. In: Medeiros LJ, Miranda RN, Wang SA, Vega F, Muzzafar T, Yin CC, Bueso-Ramos CE and Lin P (eds.) Diagnostic pathology lymph nodes and spleen with extranodal lymphomas. Lippincott Williams \& Wilkins, Baltimore, MD, pp 1006-1027, 2011.

2. Dotlic S, Perry AM, Petrusevska G, Fetica B, Diebold J, MacLennan KA, Müller-Hermelink HK, Nathwani BN, Boilesen E, Bast M, et al: Classification of non-Hodgkin lymphoma in South-eastern Europe: Review of 632 cases from the international non-Hodgkin lymphoma classification project. Br J Haematol 171: 366-372, 2015.

3. Park S and Ko YH: Peripheral T cell lymphoma in Asia. Int J Hematol 99: 227-239, 2014.

4. Pileri SA, Weisenburger DD, Sng I, Nakamura S, MullerHermelink HK, Chan WC and Jaffe ES: Peripheral T-Cell Lymphoma, NOS. In: Swerdlow EH, Harris NL, Jaffe ES, Pileri SA, Stein H, Thiele J (eds.) WHO classification of tumours of haematopoietic and lymphoid tissues. IARC, Lyon, pp 403-407, 2017.

5. Zheng Z, Tian R and Wang P: Roles of KAI1 and nm23 in lymphangiogenesis and lymph metastasis of laryngeal squamous cell carcinoma. World J Surg Oncol 15: 211, 2017.

6. Durán E, Cárdenas JM, Reina MÁ and Arriazu R: Loss of Nm23 is associated with a more favorable tumor microenvironment in patients with breast cancer. Histol Histopathol 30: 345-352, 2015.

7. Khera L, Paul C and Kaul R: Hepatitis C Virus E1 protein promotes cell migration and invasion by modulating cellular metastasis suppressor Nm23-H1. Virology 506: 110-120, 2017.

8. Radović S, Dorić M, Hukić A, Babić M, Kuskunović S and Spahović N: Immunohistochemical expression and significance of NM23 suppressor protein in primary gastric adenocarcinoma. Bosn J Basic Med Sci 13: 72-77, 2013.

9. Niitsu N, Nakamine H and Okamoto M: Expression of nm23-H1 is associated with poor prognosis in peripheral T-cell lymphoma, not otherwise specified. Clin Cancer Res 17: 2893-2899, 2011.

10. Niitsu N, Okabe-Kado J, Kasukabe T, Yamamoto-Yamaguchi Y, Umeda $\mathrm{M}$ and Honma Y: Prognostic implications of the differentiation inhibitory factor $\mathrm{nm} 23-\mathrm{H} 1$ protein in the plasma of aggressive non-Hodgkin's lymphoma. Blood 94: 3541-3550, 1999.

11. Niitsu N, Nakamine H, Okamoto M, Akamatsu H,Higashihara M, Honma Y, Okabe-Kado J and Hirano M: Clinical significance of intracytoplasmic nm23-H1 expression in diffuse large B-cell lymphoma. Clin Cancer Res 10: 2482-2490, 2004.

12. Zhou Z, Liu S, Zhang M, Zhou R, Liu J, Chang Y and Zhao Q: overexpression of topoisomerase 2-alpha confers a poor prognosis in pancreatic adenocarcinoma identified by co-expression analysis. Dig Dis Sci 62: 2790-2800, 2017.

13. Chen D, Maruschke M, Hakenberg O, Zimmermann W, Stief CG and Buchner A: TOP2A, HELLS, ATAD2, and TET3 are novel prognostic markers in renal cell carcinoma. Urology 102: 265. e1-e7, 2017.

14. Ito F, Furukawa $\mathrm{N}$ and Nakai T: Evaluation of TOP2A as a predictive marker for endometrial cancer with Taxane-containing adjuvant chemotherapy. Int J Gynecol Cancer 26: 325-330, 2016

15. El Rebey HS, Aiad HA, Abulkheir IL, Asaad NY, El-Wahed MM, Abulkasem FM and Mahmoud SF: The predictive and prognostic role of topoisomerase II $\alpha$ and tissue inhibitor of metalloproteinases 1 expression in locally advanced breast carcinoma of egyptian patients treated with anthracycline-based neoadjuvant chemotherapy. Appl Immunohistochem Mol Morphol 24: $167-178,2016$.
16. Brizova H, Kalinova M, Krskova L, Mrhalova M and Kodet R: A novel quantitative PCR of proliferation markers (Ki-67, topoisomerase IIalpha and TPX2): An immunohistochemical correlation, testing, and optimizing for mantle cell lymphoma. Virchows Arch 456: 671-679, 2010.

17. Hans CP, Weisenburger DD, Greiner TC, Gascoyne RD, Delabie J, Ott G, Muller-Hermelink HK, Campo E, Braziel RM, Jaffe ES, et al: Confirmation of the molecular classification of diffuse large B-cell lymphoma by immunohistochemistry using a tissue microarray. Blood 103: 275-282, 2004.

18. Heo MH, Park HY, Ko YH, Kim WS and Kim SJ: IRF4/MUM1 expression is associated with poor survival outcomes in patients with peripheral T-cell lymphoma. J Cancer 8: 1018-1024, 2017.

19. Wang Y, Nakayama M, Pitulescu ME, Schmidt TS, Bochenek ML, Sakakibara A, Adams S, Davy A, Deutsch U, Lüthi U, et al: Ephrin-B2 controls VEGF-induced angiogenesis and lymphangiogenesis. Nature 465: 483-486, 2010.

20. Medinger M, Fischer N and Tzankov A: Vascular endothelial growth factor-related pathways in hemato-lymphoid malignancies. J Oncol 2010: 729725, 2010.

21. Koh YW, Park C, Yoon DH, Suh C and Huh J: Prognostic significance of COX-2 expression and correlation with Bcl-2 and VEGF expression, microvessel density and clinical variables in classical Hodgkin lymphoma. Am J Surg Pathol 37: 1242-1251, 2013.

22. Yang J, Li W, He X, Zhang G, Yue L and Chai Y: VEGF overexpression is a valuable prognostic factor for non-Hodgkin's lymphoma evidence from a systemic meta-analysis. Dis Markers 2015: 786790, 2015

23. Carbone PP, Kaplan HS, Musshoff K, Smithers DW and Tubiana M: Report of the committee on Hodgkin's disease staging classification. Cancer Res 31: 1860-1861, 1971.

24. International Non-Hodgkin's Lymphoma Prognostic Factors Project: A predictive model for aggressive non-Hodgkin's lymphoma. N Engl J Med 329: 987-994, 1993.

25. Lee WJ, Kim YJ, Lee YJ, Won CH, Chang SE, Choi JH and Lee MW: Vascular endothelial growth factor protein expression is associated with a poor prognosis in patients with cutaneous extranodal natural killer/T-cell lymphoma. Br J Dermatol 178: e11-e12, 2018.

26. Chen JG, Chen HZ, Zhu J, Yang YL, Zhang YH, Huang PX, Chen YS, Zhu CY, Yang LP, Shen K, et al: Cancer survival in patients from a hospital-based cancer registry, China. J Cancer 9: 851-860, 2018

27. Krzanowski M, Drelicharz L, Belowski A, Partyka L, Sumek-Brandys B, Ramakrishnan PK and Nizankowski R: Costs of Real-life endovascular treatment of critical limb ischemia: Report from Poland-A European union country with a low-budget health care system. Ann Vasc Surg 31: 111-123, 2016.

28. Piccaluga PP, Agostinelli C, Gazzola A, Mannu C, Bacci F, Sabattini E and Pileri SA: Prognostic markers in peripheral T-cell lymphoma. Curr Hematol Malig Rep 5: 222-228, 2010.

29. Suzuki T, Kawamoto K, Tamura S, Uemura S, Kaihatsu A Nemoto H, Kobayashi H, Ushiki T, Fuse K, Shibazaki Y, et al: Peripheral T-cell lymphoma, not otherwise specified: A retrospective single-center analysis. Rinsho Ketsueki 58: 905-911, 2017 (In Japanese).

30. Lee Y, Uhm JE, Lee HY, Park MJ, Kim H, Oh SJ, Jang JH, Kim K, Jung CW, Ahn YC, et al: Clinical features and prognostic factors of patients with "peripheral T cell lymphoma, unspecified'. Ann Hematol 88: 111-119, 2009.

31. Gallamini A, Stelitano C, Calvi R, Bellei M, Mattei D, Vitolo U, Morabito F, Martelli M, Brusamolino E, Iannitto E, et al: Peripheral T-cell lymphoma unspecified (PTCL-U): A new prognostic model from a retrospective multicentric clinical study. Blood 103: 2474-2479, 2004.

32. Yang QP, Zhang WY, Yu JB, Zhao S, Xu H, Wang WY, Bi CF, Zuo Z, Wang XQ, Huang J, et al: Subtype distribution of lymphomas in Southwest China: Analysis of 6,382 cases using WHO classification in a single institution. Diagn Pathol 6: 77, 2011.

33. Vose J, Armitage J and Weisenburger D; International T-Cell Lymphoma Project: International peripheral T-cell and natural killer/T-cell lymphoma study: Pathology findings and clinical outcomes. J Clin Oncol 26: 4124-4130, 2008.

34. Federico M, Bellei M, Marcheselli L, Schwartz M, Manni M, Tarantino V, Pileri S, Ko YH, Cabrera ME, Horwitz S, et al: Peripheral T cell lymphoma, not otherwise specified(PTCL-NOS). A new prognostic model developed by the International $\mathrm{T}$ cell Project Network. Br J Haematol 181: 760-769, 2018. 
35. Chihara D, Fanale MA, Miranda RN, Noorani M, Westin JR, Nastoupil LJ, Hagemeister FB, Fayad LE, Romaguera JE, Samaniego F, et al: The survival outcome of patients with relapsed/refractory peripheral T-cell lymphoma-not otherwise specified and angioimmunoblastic T-cell lymphoma. Br J Haematol 176: 750-758, 2017.

36. Mak V, Hamm J, Chhanabhai M, Shenkier T, Klasa R, Sehn LH, Villa D, Gascoyne RD, Connors JM and Savage KJ: Survival of patients with peripheral T-cell lymphoma after first relapse or progression: Spectrum of disease and rare long-term survivors. J Clin Oncol 31: 1970-1976, 2013.

37. Weisenburger DD, Savage KJ, Harris NL, Gascoyne RD, Jaffe ES, MacLennan KA, Rüdiger T, Pileri S, Nakamura S, Nathwani B, et al: Peripheral T-cell lymphoma, not otherwise specified: A report of 340 cases from the International Peripheral T-cell Lymphoma Project. Blood 117: 3402-3408, 2011.

38. Xu P, Yu D, Wang L, Shen Y, Shen Z and Zhao W: Analysis of prognostic factors and comparison of prognostic scores in peripheral $\mathrm{T}$ cell lymphoma, not otherwise specified: A single-institution study of 105 Chinese patients. Ann Hematol 94: 239-247, 2015

39. Savage KJ, Harris NL, Vose JM, Ullrich F, Jaffe ES, Connors JM Rimsza L, Pileri SA, Chhanabhai M, Gascoyne RD, et al: ALK-anaplastic large-cell lymphoma is clinically and immunophenotypically different from both ALK+ ALCL and peripheral T-cell lymphoma, not otherwise specified: Report from the International Peripheral T-Cell Lymphoma Project. Blood 111: 5496-5504, 2008.

40. Marioni G, Cappellesso R, Ottaviano G, Fasanaro E, Marchese-Ragona R, Favaretto N, Giacomelli L, Guzzardo V, Martini A, Fassina A and Blandamura S: Nuclear nonmetastatic protein $23-\mathrm{H} 1$ expression and epithelial-mesenchymal transition in laryngeal carcinoma: A pilot investigation. Head Neck 40 : 2020-2028, 2018.
41. Fu JW and Chu XQ: Correlation between non-metastatic protein 23 expression and clinicopathological features of colorectal cancer in Asians. Genet Mol Res 14: 15597-15608, 2015.

42. Yuan L, Chen L, Qian K, Qian G, Wu CL, Wang X and Xiao Y: Co-expression network analysis identified six hub genes in association with progression and prognosis in human clear cell renal cell carcinoma (ccRCC). Genom Data 14: 132-140, 2017.

43. Piao J, Sun J, Yang Y, Jin T, Chen L and Lin Z: Target gene screening and evaluation of prognostic values in non-small cell lung cancers by bioinformatics analysis. Gene 647: 306-311, 2018.

44. Li K, Sun H, Lu Z, Xin J, Zhang L, Guo Y and Guo Q: Value of $\left[{ }^{18} \mathrm{~F}\right] \mathrm{FDG}$ PET radiomic features and VEGF expression in predicting pelvic lymphatic metastasis and their potential relationship in early-stage cervical squamous cell carcinoma. Eur J Radiol 106: 160-166, 2018.

45. Han W, Zhang C, Cao FY, Cao F, Jiang L and Ding HZ: Prognostic and clinicopathological value of NM23 expression in patients with breast cancer: A systematic review and meta-analysis. Curr Probl Cancer 41: 80-93, 2017.

46. Niitsu N, Nakamine H, Okamoto M, Akamatsu H, Honma Y, Higashihara M, Okabe-Kado J and Hirano M; Adult Lymphoma Treatment Study Group, ALTSG: Expression of nm23-H1 is associated with poor prognosis in peripheral T-cell lymphoma. Br J Haematol 123: 621-630, 2003.

47. Cuadros M, Dave SS, Jaffe ES, Honrado E, Milne R, Alves J, Rodríguez J, Zajac M, Benitez J, Staudt LM and Martinez-Delgado B: Identification of a proliferation signature related to survival in nodal peripheral T-cell lymphomas. J Clin Oncol 25: 3321-3329, 2007. 